\title{
The 21st Century Teacher Training Model with Online Mode: A Case Study Implementation of the Indonesian Virtual Coordinator
}

\author{
Ahmad Saeroji ${ }^{1}$, Muhsin ${ }^{2}$, Wisudani Rahmaningtyas ${ }^{3}$, Julia Kevin ${ }^{4}$ \\ \{saeroji@mail.unnes.ac.id ${ }^{1}$, muhsin@mail.unnes.ac.id ${ }^{2}$, wisudani.rahmaningtyas@mail.unnes.ac.id ${ }^{3}$, \\ kevinjulia789@gmail.com $\left.{ }^{4}\right\}$ \\ Universitas Negeri Semarang, Indonesia ${ }^{1,2,3,4}$
}

\begin{abstract}
This study's objectives were to find out how the implementation of online virtual coordinators conducted by the Ministry of Education and Culture in collaboration with SEAMEO and SEAMOLEC. This study uses research and reporting done with a qualitative descriptive approach. Qualitative descriptive research conducted to explain or describe an event. The results showed that the Indonesian Virtual Coordinator Training was to provide participant skills to be able to manage to learn or manage training online. Training consists of technical activities promoting online training. Make attractive flyers and secure online registration links. Besides, there are functional materials for creating or managing rooms (using virtual spaces) using Webex, mastering hosting techniques, moderators, speakers, and how to become a participant. The final result that becomes an evaluation of Indonesian Virtual Coordinator activities is that participants can create digital flyers, make a digital presence, and record material exposure activities using room Webex. Participants who meet the graduation qualifications receive a certificate as Virtual Coordinator's Training and can become instructors for further training.
\end{abstract}

Keywords: Indonesian Virtual Coordinator, Teacher Competence, 21st Century Teachers.

\section{Introduction}

According to Mahmud in Hasanah [1], the importance of teacher professionalism is to achieve national education goals. Professionalism is needed so that results can be obtained. These are included in making and implementing policies in field education at the elementary school level and win, both public and private. Government efforts to improve teacher professionalism carried out by the government bring out with various kinds of training. Besides, Tomajahu [2] conducted a study showing a difference in the ability of a teacher's teaching competition who often attended the training. This is because it has a relationship between the teacher's work experience with competencies that are directly or indirectly possessed.

Thus, it is necessary to carry out various forms of education and training for a teacher equally. Teacher education and training are the basic needs of a professional teacher who is the vanguard in advancing knowledge in Indonesia. The challenge of mastering technology for educators is needed now. Educators have the responsibility and role for future improvement through education [3][4][5]. 
The teacher profession is a profession that demands always to develop themselves through lifelong learning. It is to support the delivery of material to students so that teachers in delivery learning always provide new knowledge and be up to date on time. Teachers are required to follow the development of science and technology and the changing times to be transmitted to their students. Ideally, teachers must appear at the forefront in terms of mastery of science, technology, and current development [6].

The industrial revolution 4.0 impact all aspects of life. Education is one of the fields affected by the industrial revolution of 4.0. Teachers are currently required to be able to do online learning. A study by Cruickshank, Jenkins, and Metcalf asserts that teachers need to master ICT for their learning needs [7].

Teacher self-development can do through functional education and functional training and teacher collective activities. Education and technical training activities are the operational activities of teachers in attending school or training to improve the professionalism of teachers concerned within a specific time. The types of events can be courses, training, upgrading, and various other forms of education and training. Teachers can participate in functional education and training activities, based on assignments either by the principal or other institutions, as well as on their own accord from the teacher concerned. In contrast, the teacher's collective activity is the teacher's activity in participating in scientific meetings or participating in joint actions undertaken by the teacher, which aims to increase the professionalism of the teacher concerned. The teacher can take part in the teacher's collective activities based on the assignment either by the principal or other institution, as well as on the teacher's wishes. The types of events can be in the form of a) Participating in workshops or activities of teacher working groups/ subject teacher deliberations or inhouse training for the preparation of curriculum tools and learning activities including ICT-based learning, assessment, development of instructional media, and other activities for teacher professional development activities. b) Attending, either as a discussant or as a participant, at a seminar, colloquium, panel discussion, or other forms of a scientific meeting. c) Participate in other collective activities by the duties and obligations of teachers related to professional development.

On the other hand, the teacher required to do his professional development and the teacher doing class learning to conduct learning and deliver material in front of the class to students. When in active learning, the teacher is required not to leave the level. So that they cannot attend functional education and training in collective teacher activities; for this reason, online teacher development solutions need to do.

Indonesia is the largest archipelago country in the world, many teachers work scattered and remote areas, which forces the problem of the mobility of teacher professional development. Teacher self-development requires schools to send only one or a small part of the assembly to be present in the subject teacher deliberations, usually carried out in cities or downtownfurthermore, financial challenges and limited human resources. The current implementation of teacher development with the conventional model provides limited space for teachers to develop and exchange knowledge with others [8]. In addition distance training makes it easy to serve many participants and a large number of trainings [9][10][11][12].

Answering this challenge, the Ministry of Education and Culture, in collaboration with SEAMEO and SEAMOLEC, held virtual training called the Indonesian Virtual Coordinator. This activity conceived in free online training. For this reason, in this study was formulated by how the implementation of online virtual coordinators conducted by the Ministry of Education and Culture in collaboration with SEAMEO and SEAMOLEC as an effort. 


\section{Research Methods}

To achieve the objectives of this research is to know how the implementation of the online virtual coordinator conducted by the Ministry of Education and Culture in collaboration with SEAMEO and SEAMOLEC, this research was conducted by a qualitative descriptive approach. Qualitative graphic means to explain or describe something in the real sense and by the incident. Data obtained by conducting participatory documentation and research, in which the author participated in these activities.

\section{Literature Review}

\subsection{The Definition of Competence}

Competence is a description of the qualitative nature of one's behavior. According to Lefrancois, defining Competence is a capacity to do something produced from the learning process. After learning, the individual succeeds in learning or doing intricate work from before becoming better.

Thus competence can be interpreted as long-standing sustainability that causes a person or individual can perform absolute performance. Besides, Cowell defines the competency of an active skill. Competencies categorized ranging from simple or basic level to more difficult or complicated that will relate to the process of preparing materials or learning experiences which consist of: (1) Mastery of at least necessary competencies, (2) basic competency practices, and (3) addition of improvement or development towards competence or skills. All three processes can continue as long as there is still an opportunity to improve or develop their ability [1].

According to Hasanah [1], teachers who work need to have professional competence that always improves and sustainably develops qualifications and academic competencies in line with technology and arts development. A teacher's skill needs to have three competencies, namely personal, educational, and professional competencies. Personality competencies related to a teacher in interacting socially and following the norms and ethics that apply in the nation and state-society that can set as an example. Pedagogical competition of a teacher with the ability to organize a quality learning process. Whereas professional competence, namely, a teacher, must always improve and develop academic qualifications and competencies on an ongoing basis.

Based on some of the descriptions above, it can conclude that competence is something that describes the potential, knowledge, skills, and attitudes assessed related to a particular profession that can be actualized and realized in the form of actions or performance to carry out his job.

\subsection{Teacher Competency}

According to Government Regulation Number 19 of 2005 [13], educators must have academic qualifications and competencies as agents of learning, physically and mentally healthy, and realize national education goals. A teacher's skills include pedagogic competence, personality competence, professional competence, and social competence. The competency of a teacher must always be improved and developed by the development of science and technology. 
Pedagogical competence is competency in managing quality learning and active learning. Personality competence is competence related to a teacher's ethics in social interaction, both with fellow teachers or fellow students who can use as role models. Whereas professional expertise is competence associated with the mastery of scientific material of a teacher in his field. The last is competence in interacting in social life.

\subsection{Teacher Competency Improvement}

Teachers' efforts to improve their competence can do through: First, continuing education levels, attending teacher working groups / subject teacher deliberations, training, upgrading workshops, seminars, and enhancing performance. Second, carried out by the principal through (a) sending teachers to attend training, upgrading, workshops and seminars, (b) disseminating training results and various government policies by inviting speakers; (c) conduct computer and English language training; (d) encourage teachers to continue their studies by government demands; (e) conduct comparative studies to other schools that are considered more advanced; (f) sending teachers for internships to other schools; g) complete the facilities and various supporting media for learning activities; (h) provide awards for outstanding teachers; i) improve teacher welfare by providing additional income from school committees and parents; (j) provide role models, encouragement, and inspire the teacher's conscience so that they are aware of the duties and responsibilities as a teacher. Three, communities have participated through school committees with fundraising to smooth the learning process, including teacher training activities, seminars, workshops, and assisting teachers to continue their studies. Fourth, an increase in the teaching profession through teacher working groups/ subject teacher deliberations, which are forums for teachers to share and improve their competence. Fifth, government efforts activities are training, upgrading, and workshops.

\subsection{The 21st Century Teacher}

Changes in technology and character of the society that occurred in the 21 st century have implications for the characteristics of teachers. In a progressive view, changes in the character of the community need to be accompanied by the teacher in the learning process. So if the city has changed to a digital society, the teacher needs to immediately transform himself both technically and socio-culturally to adapt to existing developments.

According to the head of the division of the PGRI (Teachers Association of the Republic of Indonesia), teachers must begin to get used to feeling the digital learning that continues to grow. Because the use of technology in education is useful for facilitating quality learning.

Characteristics of 21st-century teachers include: (1) the teacher aside from being a facilitator, must also be a motivator and inspiration. (2) teachers must be able to transform themselves in a cyber pedagogic or digital era that must always increase their interest in reading or literacy. (3) the teacher must have writing skills. (4) teachers must be creative and innovative and continually improve the quality of ICT-based learning. (5) teachers must be able to carry out the cultural transformation, transforming the process of change and change from what is considered old to new [14].

The 21st-century teacher's mastery of ICT is a necessity for always developing. Because in the 21 st-century, learning is not only conventionally face to face in front of the class, but it did online [15][16].

The level of ICT competencies that should be owned by a teacher or instructor must be familiar with ICT, where the teacher must quickly use ICT with the demands of learning 
needs, the competencies they have. ICT plays a very important role in current educational activities [15][7][16][17].

\subsection{Indonesian Virtual Coordinator}

Indonesian Virtual Coordinator is the concept of adopting an Online Learning Community derived from the idea of "community of practice" or COF. COF is a community that consists of a group of people who are practically sharing and interest in achieving common goals [8]. With a particular interest group or an online forum, group members learn to explain problems associated with practice and make decisions to overcome them and improve skills [18]. In this research, the application of OLC in Indonesia is called the Indonesian Virtual Coordinator. The training activities carried out online, which in this activity utilizes the internet network with the Webex application. Indonesian Virtual Coordinator is an online education and training program like what was announced by Nisa [19] states that education and training are a training or training program that is delivered separately between lecturers and training participants more flexible in the form of online and technology utilization. University of Vermont berhasil menerapkan kursus online di Amerika [11].

The Indonesian Virtual Coordinator training activity organized to answer the challenges of 21 st-century teacher self-development, which changed from regular teacher self-development to virtual teacher self-development. There are many advantages to implementing virtual training for teacher self-development. For example, it is flexible for teachers as members of subject study groups or Subject Teachers Meetings to participate in ongoing activities and collaborative learning whenever and wherever. This is also to foster a sense of sharing and provide sustainability support to teachers [8][20]. The importance of ICT to support collaboration and reflection, because using ICT-based training can facilitate access to material and collaborate with colleagues as in the real world [7][16]. Through teleconferencing the training participants maintain face-to-face interaction between the instructor and the participant [5].

Indonesian Virtual Coordinator provides a virtual environment for group members or communities to learn and interact with each other. This is to appreciate the contribution of each member regardless of his professional status and social background. Indonesian Virtual Coordinator participants share and are not dependent on an expert to provide material or knowledge. In presenting content in the Indonesian Virtual Coordinator, each respective participant gave their field of study and expertise. The primary purpose of the Indonesian Virtual coordinator's implementation is to equip participants to manage training or online seminars [21]. Today many organizations are developing remote work activities. This responds to the challenge of the rapid development of ICT [22][23][7][24].

Effective distance training is carried out to build a collaborative learning environment. Distance training has a very broad reach space. Virtual platforms are the key to collaborating with each other [25][11]. Virtual coordinator training is carried out with concepts that share with each other in the territory of Indonesia. this is done to improve the quality of education in Indonesia.

Virtual Coordinator Training is the biggest online training platform for teachers. The concept of the Indonesian Virtual Coordinator is Dr. Gatot Hari Prijowirjanto inviting 3 Indonesian Teachers to compile the idea of a Virtual Coordinator that adapted to the conditions of teachers in Indonesia. The background of the formation of Virtual Coordinator Training is the Challenge of Industrial Revolution 4.0; Indonesia, especially in the field of Education, must be prepared. Sharing broader knowledge is needed. The icon channel in 
Indonesia (Tuesday Online Seminar and Workshop in the network) is not enough the Indonesian Teachers Association with its program called Saresehan in the network.

\section{Results and Discussion}

\subsection{Teacher Competency Development Through Virtual Coordinator Training}

\subsubsection{History of Indonesian Virtual Coordinator}

The first founder of the Indonesian Virtual Coordinator consisted of Dr. Gatot HP, Dr. Anggai Sajarwo (Seames Bangkok), Achmad Purnomo (Seames Bangkok), Khairudin, S.Pd., M.Pd (Senior High School Teachers in East Aceh), Siti Zulaiha, S.Pd (Junior High School Teacher in Wonogiri), Umi Tira Lestari, SE., M.Ak (Vocational Teacher in Bogor). From the founder of the Virtual Coordinator, which began with three Indonesian teachers who participated in the training, it grafted in the development of the Virtual Coordinator Training, which adjusted to the teachers in Indonesia [26].

\subsubsection{Implementation of Indonesian Virtual Coordinator}

Indonesian Virtual Coordinator is training conducted online with the aim that after completing training, participants can manage the training online. As for the registration and implementation carried out by the steps:

1) Registration also is done using a google form, where the link spread on various social media (WhatsApp, Facebook, Twitter, and website or blog), and using a digital Flyer.

2) The selection process based on the registrant through the google form link and participant restrictions. The number of instructors adjusted according to the number of comparisons between instructors and the number of participants. If the quota met, then those who cannot qualify can register in the next batch. Information on the registration link can be seen in Figure 1.

3) For participants who qualify will be created WhatsApp group to coordinate online and conduct training can be seen in Figure 2.

4) Online teleconference training using the Webex video-conferencing application. Each participant should be a Host, Speaker, and Moderator. Participants' obligation to be hosts, presenters, moderators every two times and participated in as many as six times can be seen in Figure 3.

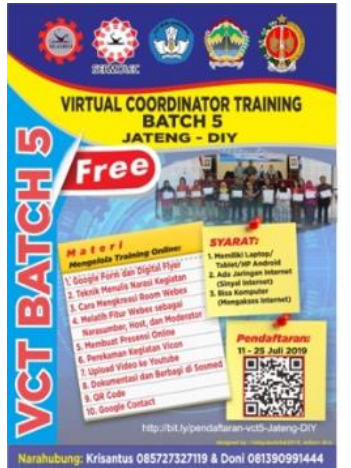

Fig. 1. Implementation Flyer of the Virtual Coordinator Training 

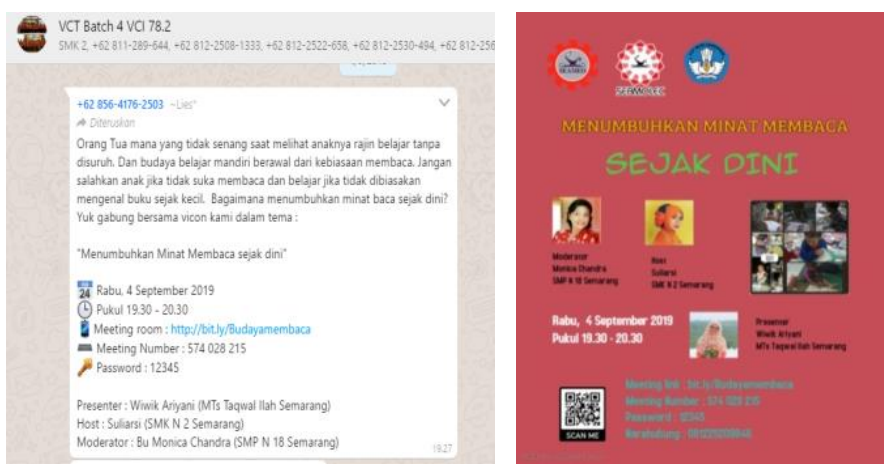

Fig. 2. WhatsApp Group Online Coordination and Information on the Implementation of the Teleconference

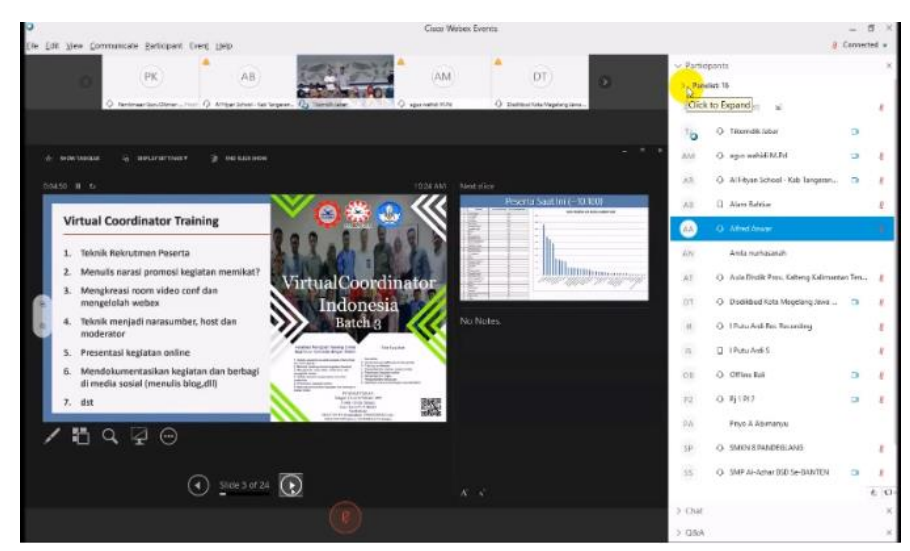

Fig. 3. Display the Delivery of Material with Webex

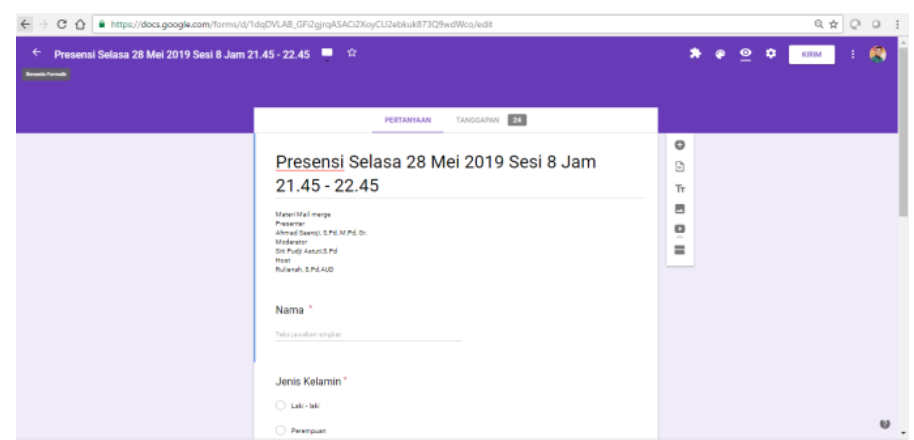

Fig. 4. Presence of Online Activities

For proof of the implementation of the task by making digital leaflets, digital presence (with google forms and Zoho forms), and recording computer screens during presentations by screen recorder applications or laptop computers. 
1) Task Collection, when the task is done, must be collected online. Where the jobs that must be received by the participants are six flyer presence as host, moderator, presenter, and attendance as a participant and a link to upload recordings of online presentations by YouTube. To display the collection of tasks figure 5.

2) An assessment of the assignment is carried out by the instructor. Participants who pass will get a certificate from Seameo and are entitled to the opportunity to become instructors in the next batch can be seen in Figure 6.

3) For a virtual flow of training, Coordinator activities can see in the figure 7.

4) The process of developing a virtual coordinator training in Indonesia carried out in stages. Which can describe in the figure 8.

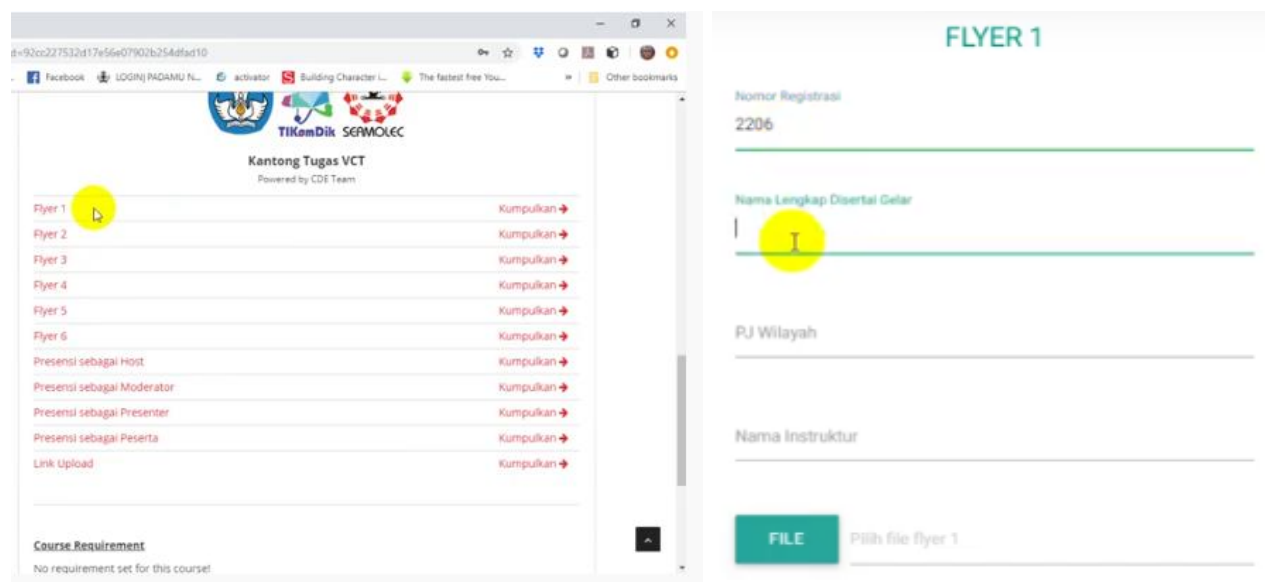

Fig. 5. Collection of VCTI Tasks

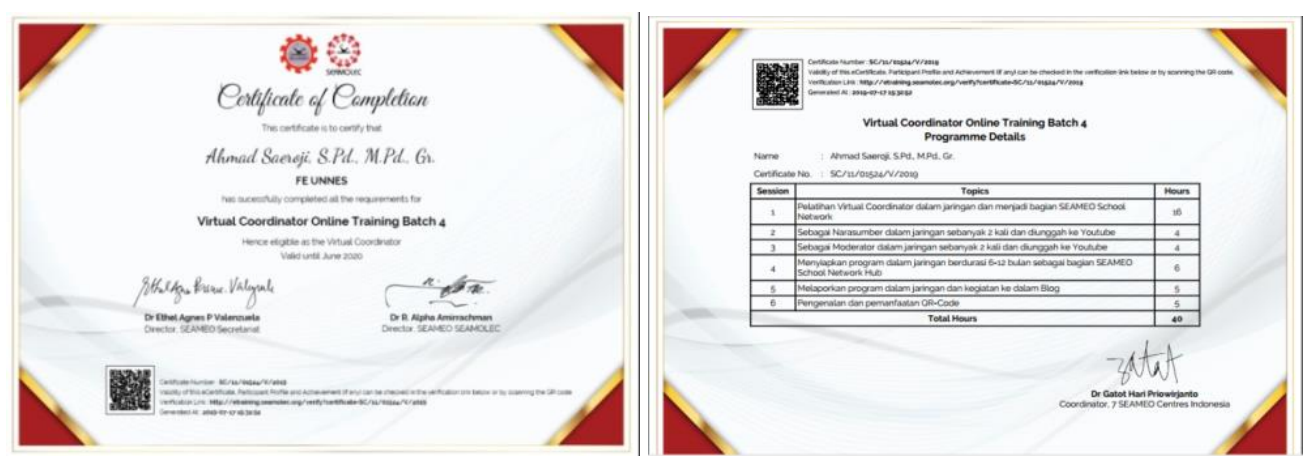

Fig. 6. For participants have pass the task, will get an online certificate 


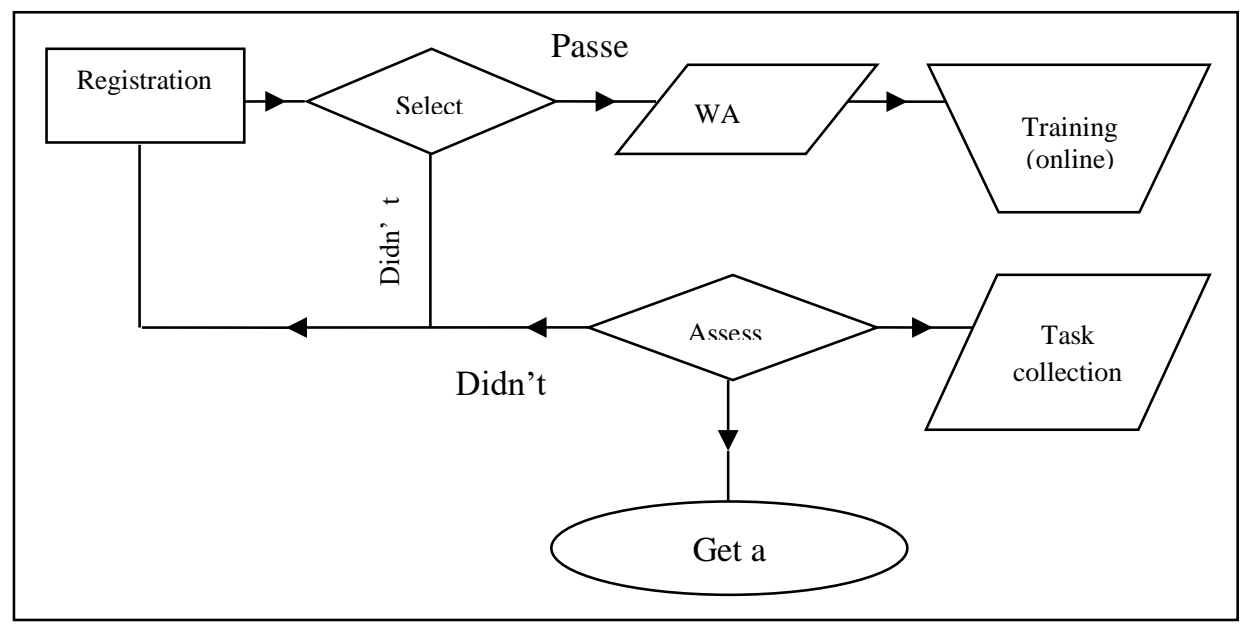

Fig. 7. Virtual Coordinator Training Flow

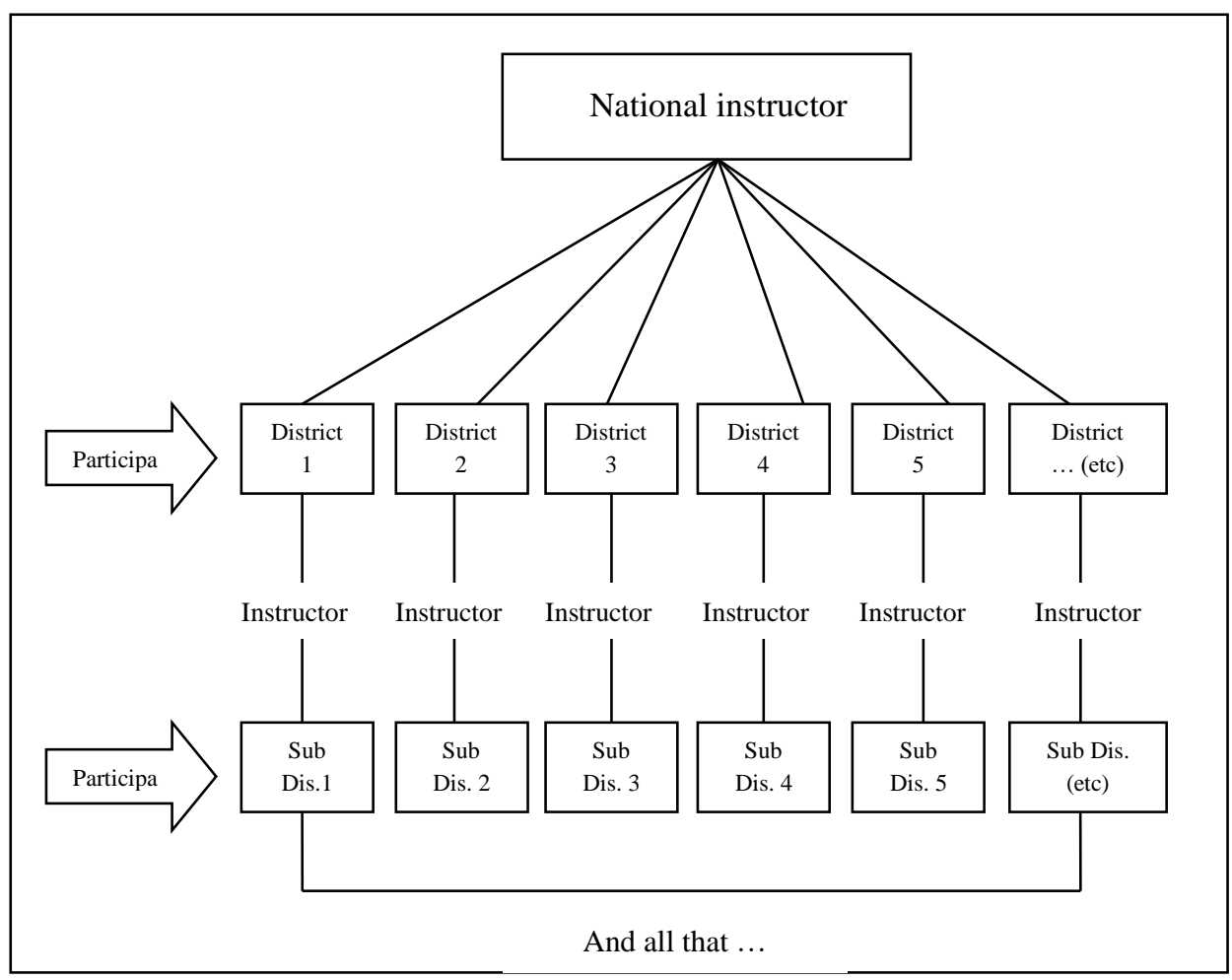

Fig 8. Picture of cadre in developing Virtual Coordinator Training 


\section{Conclusion}

The results showed that the Indonesian Virtual Coordinator Training was to provide participants' skills to be able to manage to learn or manage online training. Activities undertaken in the Indonesian Virtual Coordinator training consist of techniques to promote online training or seminars by creating attractive digital leaflets and creating online registration links, techniques for creating or managing rooms using Webex, mastering hosting techniques, moderators, speakers, and how to become a participant. The final result for evaluating the Virtual Indonesia coordinator's activities is that participants can make digital flyers, make a digital presence, and record material exposure activities using the Webex space. Participants who meet the graduation qualifications receive a certificate as Virtual Training Coordinator and have the opportunity to become instructors for further training. Suggestions for further research are to test the effectiveness of virtual coordinator training activities in Indonesia.

\section{References}

[1] N. Hasanah, "Pengaruh penerapan problem based learning melalui strategi belajar preview, question, read, reflect, recite, and review terhadap kemampuan berpikir kritis, hasil belajar kognitif, dan hasil belajar afektif siswa kelas VII SMPN 18 Balikpapan.” Universitas Negeri Malang, 2012.

[2] M. L. Stürmer, S., Ihme, T. A., Fisseler, B., Sonnenberg, K., \& Barbarino, "Promises of structured relationship building for higher distance education: Evaluating the effects of a virtual fast-friendship procedure," Comput. Educ. J., 2018.

[3] S. S. Çelen, F. K., Çelik, A., \& Seferoğlu, "Analysis of Teachers'Approaches to Distance Education," Procedia-Social Behav. Sci., pp. 388-392, 2013.

[4] Z. Samigulina, G., \& Samigulina, "Intelligent System of Distance Education of Engineers, based on Modern Innovative Technologies," 2nd Int. Conf. High. Educ. Adv., pp. 21-23, 2016.

[5] L. D. Sandrone, S., \& Schneider, "With social distancing and uncertainty about the complete reopening of laboratories and campuses, there is a pressing need for a more flexible educational experience. Seizing this opportunity to integrate active learning into adaptive curricula can fastf," Neuron, vol. 106, 2020.

[6] O. M. Anwas, "Kebutuhan Diklat Online untuk Tenaga Pendidik," J. Teknol. Pendidik., pp. 1938,2006

[7] H. Holmgren, "Preparations for practical exercises in vocational education: Can ICT-based distance instruction be an alternative to face-to-face instruction? An empirical contribution," Soc. Behav. Sci., vol. 46, pp. 1152-1161, 2012.

[8] E. R. Sari, "Online learning community: a case studi of teacher profesional development in Indonesia," Instercultural Educ., pp. 63-72, 2012.

[9] P. Ilgaz, H., \& Paskar, "The Contribution of Technology Acceptance and Community Feeling to Learner Satisfaction in Distance Education," Procedia - Soc. Behav. Sci., vol. 106, pp. 26712680, 2013.

[10] I.-S. Chen, "Work engagement and its antecedents and consequences: A case of lecturers teaching synchronous distance education courses," Comput. Human Behav., pp. 1-9, 2016.

[11] J. T. Clark, "Distance education," Clin. Eng. Handb., pp. 400-415, 2020.

[12] R. d. Meijs, C., Neroni, J., Gijselaers, H. J., Leontjevas, R., Kirschner, P. A., \& Groot, "Motivated Strategies for Learning Questionnaire Part B Revisited: New Subscales for an adult Distance Education Setting," Internet High. Educ., 2018.

[13] Kemdikbud, Peraturan Pemerintah (PP) Nomor 19 Tahun 2005 tentang Standar Nasional Pendidikan. Jakarta: Menteri Hukum dan HAM, 2005. 
[14] E. Wahyono, "UT Goes Green: Model Pendidikan Karakter," Jakarta: Direktorat Ketenagaan Dikti, 2011.

[15] S. Yarmohammadian, M. H., Ahmadi, A., \& Mehdi, "Evaluasion of distance education programs based on the NADE-TDEC 2009-10," Procedia -Social Behav. Sci., pp. 117-119, 2011.

[16] M. Kaya, "Distance education systems used in universities of Turkey and Northern Cyprus," Procedia - Soc. Behav. Sci., vol. 31, pp. 676-680, 2012.

[17] S. Semradova, I., \& Hubackova, "Teacher responsibility in distance education.," Procedia Soc. Behav. Sci., vol. 217, pp. 544 - 550, 2016.

[18] T. McNeil, Assessing the gap between community development practice and regional development policy. Toronto: Oxford University Press, 1997.

[19] I. F. Nisa, "Studi Pengelolaan Diklat Interaksi Online (DIO) Widyaiswara," Skripsi UNNES, 2016.

[20] R. H. Neroni, J., Meijs, C., Gijselaers, H. J., Kirschner, P. A., \& de Groot, "Learning strategies and academic performance in distance education," Learn. Individ. Differences, pp. 1-7, 2019.

[21] W. Giesbers, Bas; Rienties, Bart; Dirk, Tempelaar; Gijselaers, "Investigating the relations between motivation, tool use, participation," Comput. Human Behav., pp. 285-292, 2012.

[22] R. Rosen, B., Furst, S., \& Blackburn, "Training for Virtual Teams: An Investigation of Currentpractices and Future Needs," Hum. Resour. Manage., vol. 45, no. 2, pp. 229-247, 2006.

[23] S. Jowsey, T., Foster, G., Loelu, P. C., \& Jacobs, "Blended learning via distance in preregistration nursing education: A scoping review," Nurse Educ. Pract., vol. 44, pp. 1-10, 2020.

[24] R. McCutcheon, L. R., Alzghari, S. K., Lee, Y. R., Long, W. G., \& Marquez, "Interprofessional education and distance education: A review and appraisal of the current literature," Curr. Pharm. Teach. Learn., 2017.

[25] E. Rodrigues, S. J., Affonso, S. A., \& Quinelato, "Distance learning in undergraduate education: the challenges of building a collaborative environment," Procedia-Social Behav. Sci., vol. 116, pp. 3499-3501, 2014.

[26] K. A. Barata, "Virtual Coordinator Indonesia," 2019. [Online]. Available: https://krisantusardy.wordpress.com/guide-line-vct/. 